\title{
O TERRITÓRIO DO CERRADO EM DISPUTA: CONTROLE DA ÁGUA COMO ESTRATÉGIA DE ACUMULAÇÃO DE CAPITAL EM GOIÁS, BRASIL
}

\author{
Ana Paula Saragossa Corrêa ${ }^{1}$ \\ Ricardo Junior de Assis Fernandes Gonçalves ${ }^{2}$
}

Resumo: Os processos de acumulação por espoliação fizeram e fazem parte da expansão das fronteiras de lucratividade do capital hegemonizado por empresas nacionais e transnacionais na apropriação de terra, água e minérios para produção de energia e commodities agrícolas e minerais. Neste sentido, a pesquisa tem como objetivo compreender a centralidade do controle da água (superficial e em aquíferos) no processo de disputa pelo território cerradeiro no estado de Goiás. As investigações apresentadas fundamentam-se em um referencial teórico e metodológico que investiga a relação entre acumulação por espoliação e as táticas de apropriação dos territórios do Cerrado em Goiás por projetos do agrohidronegócio e produção hidroenergética. O estudo procede ainda de análises de dados secundários emitidos por instituições governamentais e não governamentais, tabelas e mapas que contemplam a problemática abordada. Por conseguinte, constatou-se que a expansão do capital no Cerrado goiano é intensiva no controle de bens comuns naturais e está integrada de maneira subordinada na Divisão Internacional do Trabalho por meio da produção de commodities.

Palavras-chave: Acumulação por espoliação; Conflitos Territoriais; Cerrado; Água.

\section{THE TERRITORY INDISPUTE: CONTROL OF WATER AS A CAPITAL ACCUMULATION IN GOIÁS, BRASIL}

\begin{abstract}
The processes of accumulation by dispossession have made and are part of the expansion of the frontiers of profitability of capital hegemonized by national and transnational companies in the appropriation of land, water and minerals for energy production and agricultural and mineral commodities. In this sense, the objective of this research is to understand the centrality of water control (surface and aquifer) in the process of dispute for the territory in the state of Goiás. The investigations presented are based on a theoretical and methodological framework that investigates the relationship between accumulation by spoliation and the tactics of appropriation of the territories of the Cerrado in Goiás by projects of the agrohydropusiness and hydropower production. The study also comes from analyzes of secondary data issued by governmental and non-governmental institutions, tables and maps that contemplate the problem addressed. Therefore, it was found that the expansion of capital in the Goian Cerrado is intensive in the control of natural common goods and is integrated in a subordinate manner in the International Division of Labor through the production of commodities.
\end{abstract}

Keywords: Primitive Accumulation; Territorial Conflicts; Wate.

\footnotetext{
${ }^{1}$ Universidade Federal de Goiás - Regional de Jataí. anap.saragossa@ gmail.com.

${ }^{2}$ Universidade Estadual de Goiás - Campus Iporá. ricardo.goncalves@ueg.br

Estudos Geográficos, Rio Claro, 17: 27-42, jan./jun. $2019 \quad$ (ISSN 1678-698X)

http://www.periodicos.rc.biblioteca.unesp.br/index.php/estgeo
} 


\section{INTRODUÇÃO}

Os processos de expansão das fronteiras de acumulação de capital com base na produção agroexportadora fomentaram o avanço da modernização conservadora da agricultura ${ }^{3}$ a partir da década de 1960 no território cerradeiro goiano. A produção agrícola se fez presente no Centro-Oeste no interior da inserção desse território na Divisão Internacional do Trabalho (SANTOS, 2004). Consequentemente, as paisagens do Cerrado foram transformadas em um domínio territorial cindido pelas estratégias econômicas dos interesses hegemônicos conectados nas redes internacionais da economia capitalista (CASTILHO; CHAVEIRO, 2010).

As ações do Estado por meio de políticas de desenvolvimento, aliadas aos interesses das empresas nacionais e transnacionais, impactaram os lugares da existência dos Povos Cerradeiros ${ }^{4}$ (MENDONÇA, 2004) e provocaram a expropriação dos seus espaços de autonomia, agudizando os conflitos por terras e água. Para Thomaz Junior (2010) a terra e a água são elementos inseparáveis para a acumulação do capital. Por conseguinte, a disponibilidade de água dos rios, aquíferos e ambientes alagadiços como as veredas nas áreas de Cerrado fomenta a construção de canais e represamentos para a agricultura irrigada e de exportação de commodities.

Outra problemática dentro do território do Cerrado goiano é o represamento dos rios para a produção hidroenergética por meio da construção de Usinas Hidrelétricas (UHs) e Pequenas Centrais Hidrelétricas ( $\mathrm{PCHs}$ ). A produção de energia é fundamental para a acumulação estratégica de capital nos setores extrativistas (mineração, agronegócio etc.) voltados para a exportação de commodities agrominerais. A posse da terra e da água, conforme Thomaz Junior (2010), pelas grandes corporações, conta com a ação do Estado para o empoderamento do capital e, por consequência, a reverberação dos efeitos negativos no quadro socioambiental dos territórios tradicionalmente ocupados por camponeses, povos indígenas e quilombolas.

Em suma, o presente estudo tem como objetivo compreender a centralidade do controle da água (superficial e em aquíferos) no processo de disputa pelo território cerradeiro no estado de Goiás. A pesquisa discute as causas dos conflitos pela água em Goiás e como estes sobrepõem aos territórios de existência coletiva dos camponeses goianos. Os procedimentos metodológicos baseiam-se em pesquisas qualitativas em fontes de documentação indireta, como notícias de jornais e dados secundários de órgãos públicos e organizações não governamentais.

Além desta introdução, a primeira parte do artigo apresenta a relação entre as estratégias de acumulação por espoliação - conforme definição apresentada por Harvey (2013) - e a apropriação privada da natureza mediante a pilhagem territorial dos bens comuns. No segundo momento a pesquisa expõe os resultados das investigações centradas nas implicações territoriais da apropriação das águas do

\footnotetext{
${ }^{3}$ Mendonça (2004, p. 166) afirma que "a modernização conservadora da agricultura foi a materialização mais expressiva do capital nas áreas de Cerrado e, é, na sua gênese, excludente, pois estava/está em acordo com a "opção brasileira" de crescimento econômico. É a face mais visível da modernização capitalista e é a condição para a territorialização das empresas rurais e das agroindústrias que conformam o espaço geográfico".

${ }^{4}$ Segundo Mendonça (2004, p. 29) "Refere-se às classes sociais que historicamente viveram nas áreas do Cerrado constituindo formas de uso e exploração da terra a partir das diferenciações naturais-sociais, experienciando formas materiais e imateriais de trabalho, denotando relações sociais de produção e de trabalho muito próprias e em acordo com as condições ambientais, resultando em múltiplas expressões culturais. Atualmente se configuram nos trabalhadores da terra, camponeses e demais trabalhadores que lutam pela terra e pela reforma agrária, territorializando ações políticas contra o capital".

Estudos Geográficos, Rio Claro, 17: 27-42, jan./jun. 2019 (ISSN 1678-698X) http://www.periodicos.rc.biblioteca.unesp.br/index.php/estgeo
} 
Cerrado pelo capital na agricultura e na produção hidroenergética. Por fim, as considerações finais apresentam uma avaliação dos principais resultados e apontam para o fato de que a inserção do Cerrado nos circuitos da acumulação capitalista é dependente dos setores extrativos e tem como centralidade a permanência do controle da terra, da água e dos minérios.

\section{O PROCESSO DE ACUMULAÇÃO DE CAPITAL POR ESPOLIAÇÃO DA NATUREZA}

A acumulação primitiva ocorre com a desapropriação dos trabalhadores do campo, processo anterior à Revolução Industrial na Inglaterra do século XVIII. "A assim chamada acumulação primitiva não é, por conseguinte, mais do que o processo histórico de separação entre produtor e meio de produção" (MARX, 2013, p. 786). Além da mais-valia, a acumulação de capital necessita de outros meios. Luxemburg (1985, p. 254) afirmou que "[...] é pura ilusão esperar que o capitalismo se contente somente com os meios de produção que for capaz de obter por via comercial". Os métodos de acumulação primitiva coexistem historicamente de forma contraditória e dialética. As estratégias desse processo, no entanto, estão embasadas na dominação, uso da força bruta, barbáries legalizadas pelo Estado, ações ilícitas e pilhagem: a acumulação primitiva supera o avanço do processo de acumulação de capital. Autores como Lencione (2012), Brandão (2010), Harvey (2013) e Moreira (2015) afirmam que os métodos da acumulação primitiva são contínuos na história do capitalismo.

São nos momentos de crise cíclica (HARVEY, 2011), no desequilíbrio e no excesso de acúmulos de capitais que a acumulação por espoliação é mais evidente. A forma de expansão do capital pelas apropriações territoriais e práticas de pilhagem tem como objetivo liberar um conjunto de ativos a baixo custo para criar capitais sobreacumulados. A prática de sobreacumulação é crônica a partir da década 1970 pelos processos neoliberais de privatizações. O Estado tem um papel importante na consolidação da prática de acumulação por espoliação. Além disso, a expansão em territórios não-capitalistas é primordial, pois o investimento do capital sobreacumulado nos lugares onde o preço da terra, a mão de obra e os insumos são baixos, resulta em ganhos altamente lucrativos (HARVEY, 2011; 2013).

Para Lencione (2012, p. 2) a espoliação significa "privar alguém de algo, por meios ilícitos, ilegítimos ou violentos". O Processo de reprodução do capital "se vincula aos diversos procedimentos que buscam se apossar do lucro, por meio da sujeição da posse e do domínio da propriedade privada" (LENCIONE, 2012, p. 2). Há diferentes formas para que a acumulação por espoliação ocorra, como a violação da propriedade intelectual, a biopirataria, a exploração dos recursos naturais, a pilhagem e a exploração cultural de camponeses e povos tradicionais. Nesse sentido, a acumulação estratégica de capital do território do Cerrado goiano acontece, primordialmente, pela espoliação da natureza. "[...] o capital transformou a questão ambiental em um grande negócio [...]. A natureza se torna, ainda segundo Neil Smith, uma estratégia de acumulação" (HARVEY, 2016, p. 231).

A espoliação do território do Cerrado ocorre de diversas maneiras. Dentre elas, para a produção de commodities agrominerais, megaprojetos hidroenergéticos, territorialização do agrohidronegócio, pelo turismo e pela indústria farmacoquímica. Estas atividades, portanto, exigem o controle e a apropriação privada da água. Dessa maneira, Aráoz (2010) assinala que a distribuição da água não é somente determinada pela natureza. A escassez ou a abundância dos recursos hídricos é

Estudos Geográficos, Rio Claro, 17: 27-42, jan./jun. 2019 (ISSN 1678-698X) http://www.periodicos.rc.biblioteca.unesp.br/index.php/estgeo 
uma questão politicamente determinada. Os usos e distribuições para os diferentes grupos sociais estão alocados através do poder. Dessa forma, o controle da água é categórico para o domínio e controle de um determinado território. O sucesso do agrohidronegócio (MENDONÇA, 2010; THOMAZ JUNIOR, 2010) está no domínio territorial e nele incluso o monopólio das terras e o controle sobre as águas.

De forma consorciada, dispor de terra e água, mais ainda, controlálas, possibilita ao capital condições para a prática da irrigação, o que reforça e intensifica a expansão territorial sobre as melhores terras para fins produtivos. Ou seja, o acesso às terras, seja pela titularidade (legal ou grilada), seja por meio de contratos de arrendamento etc., é a garantia que o capital, identificado como agronegócio (grandes grupos econômicos nacionais e transnacionais), requer para reproduzir-se e apropriar-se dos meios de produção e controlar o tecido social, mediante o acionamento dos dispositivos das esferas da produção, da circulação, da distribuição, do consumo, bem como especulativos (THOMAZ JUNIOR, 2010, p.6).

Mendonça (2015) enfatiza que há evidentes problemas socioambientais provocados pela territorialização do agrohidronegócio, por esse motivo, os conflitos no campo são constantes e crescentes no estado de Goiás. Os trabalhadores e camponeses, expulsos pelo capital hegemônico, lutam para perpetuarem em seus lugares de existência comunitária. Sendo assim, as denúncias de conflitos envolvendo a disputa da terra e do acesso à água, demonstradas nesta pesquisa, acentuam a problemática da luta dos camponeses pela reprodução social da existência nos seus territóricos.

\section{O CERRADO GOIANO E A ÁGUA COMO TERRITÓRIOS EM DISPUTA}

Uma abordagem geográfica do Cerrado permite defini-lo como,

[...] um espaço disputado por um vetor economicista e por reações políticas que, contra o economicismo, o defende como patrimônio de vida capturado pelos componentes da economia globalizada, mas afeita a novos rumos que se desdobram nas fendas dessa economia. Por isso, é um território integrado ao mundo, mas desigual e cindido em sua particularidade. Esse processo integra, numa mesma lógica, diferentes campos da vida, desde os naturais, genéticos e simbólicos, passando pelo econômico e social, até o cultural e político (CASTILHO; CHAVEIRO, 2010, p. 37).

Cerrado, um território em disputa influenciado pelos interesses hegemônicos. Os conflitos territoriais são constantes e característicos dentro do Cerrado goiano: conflitos étnicos, culturais, econômicos e políticos. Neste sentido, no âmbito do presente debate pontuam-se alguns conceitos sobre essa categoria geográfica, o território.

Raffestin (1993) propõe que o território é formado pelo poder do Estado e poder de outros atores. O território é o espaço político e de disputas em diferentes escalas.

Estudos Geográficos, Rio Claro, 17: 27-42, jan./jun. $2019 \quad$ (ISSN 1678 -698X) http://www.periodicos.rc.biblioteca.unesp.br/index.php/estgeo 
Há, portanto um "processo" do território, quando se manifestam todas as espécies de relações de poder, que se traduzem por malhas, redes e centralidades cuja permanência é variável mas que constituem invariáveis na qualidade de categorias obrigatórias. 0 território é também um produto "consumido", ou, se preferirmos, um produto vivenciado por aqueles mesmos personagens que, sem haverem participado de sua elaboração, o utilizam como meio. É então todo o problema da territorialidade que intervém permitindo verificar o caráter simétrico ou dissimétrico das relações de poder. $\mathrm{A}$ territorialidade reflete, com muita segurança, o poder que se dá ao consumo por intermédio de seus "produtos" (RAFFESTIN, 1993, p. 7).

Segundo Souza (2016, p. 58), o território se forma e consolida nas relações sociais, que se sustentam e revelam sua dimensão de classe. "Esse é o jogo específico das disputas espaciais do capital, elas encerram dimensões que assumimos como terminologias territoriais (local-global), mas que são objetivamente lutas sobre a apropriação e exclusão espacial". Nesse caso, classifica-se o território como um meio de acumulação de capital, visando efetivamente o lucro. Dessa maneira, o território pode determinar tamanha influência ocasionada pela disponibilidade de interesses dos atores hegemônicos e suas relações de poder sobre o espaço. Diante desta lógica, pergunta-se: Quem controla e se apropria do Cerrado goiano, uma vez que o território é um instrumento de poder?

O Estado fortalece a constituição do território, pois é o agente que implementa políticas e planos nas regiões. No caso desse estudo, o centro goiano e o eixo Brasília - Goiânia, a porção sul do estado com o predomínio da soja, milho, cana-de-açúcar e das indústrias transformadoras, a parte das mineradoras no Sudeste e Norte e os abatedouros concentrados nas regiões Noroeste e Central do estado de Goiás, são os territórios de maiores espoliações (consequentemente, por possuírem as maiores concentrações de capitais). "Ou seja, mesmo havendo uma tendência ou direção do capital, isso é dirigido pelos interesses dos atores hegemônicos por meio do Estado e de outras ferramentas de ações territoriais" (CASTILHO; CHAVEIRO, 2010, p. 47).

A partir da segunda metade do século XX, a produção e organização do território no Cerrado goiano adentraram em uma nova fase da Divisão Internacional do Trabalho (SANTOS, 2004) como fornecedora de commodities agrícolas. As inovações tecnológicas do século passado fizeram com que a mecanização e a tecnologia assumissem como objeto dentro do espaço geográfico, dando assim, a formatação do território através do meio técnico-científico-informacional (SANTOS, 2004).

Sendo assim,

A terra ferida, a água contaminada, a população distribuída desigualmente, a renda fraturada, a economia diferenciada nas regiões, o sujeito desenraizado são características que demonstram um contraste: pelo critério das cifras e dos índices de produtividade, o território cerradeiro é um dos mais promissores economicamente no país. Isso exige que se pense o modelo de desenvolvimento que o dinamiza e que igualmente destrói sua biodiversidade. Ou então, que o proclama por meio de imagens que ressaltam a sua importância vital, mas o abate na forma de usá-lo. Em síntese:

Estudos Geográficos, Rio Claro, 17: 27-42, jan./jun. $2019 \quad$ (ISSN 1678 -698X) http://www.periodicos.rc.biblioteca.unesp.br/index.php/estgeo 
quanto mais o Cerrado se afirma enquanto território, mais é destruído enquanto Bioma. (CHAVEIRO, 2010, p. 27)

As mudanças ocorridas no Cerrado intensificaram os problemas socioambientais nas fronteiras da acumulação de capital por meio da espoliação e pilhagem da natureza e do trabalho. Ademais, as paisagens outrora consideradas rudes e atrasadas, os solos representados como improdutivos e os territórios vazios de técnicas foram adensados por novos circuitos produtivos conectados com a lucratividade do capital hegemônico.

\begin{abstract}
Essas mudanças que tiveram como objetivo tornar o Cerrado produtivo e lucrativo alteraram de forma significativa a configuração espacial dos territórios. As antigas paisagens do Cerrado foram sendo modificadas e transformadas predominantemente em campos despovoados de gentes, mas povoados de densas técnicas, malhas, redes representadas por meio das monoculturas (soja, cana de açúcar, eucaliptais e outros), agroindústrias, empreendimentos barrageiros, mineradoras etc. $\mathrm{O}$ solo que até então era considerado de baixa produtividade, com os incrementos técnicos científicos (calcários, máquinas agrícolas de última geração, pivôs etc.) se transformou em terra de primeira e, consequentemente, tornou-se um dos fatores essenciais para a implantação do agrohidronegócio. (MENDONÇA, 2015, p. 4)
\end{abstract}

Thomaz Junior (2010) afirma que é nos conflitos territoriais que estão as problemáticas dos camponeses. As ações entre o capital e os trabalhadores, necessidade de terras planas, férteis e com disponibilidade hídrica e mecanização são exemplos das disputas territoriais e que fazem parte do processo expansionista do agrohidronegócio. As disputas territoriais estão atreladas ao processo geopolítico representado pelo Estado e as empresas transnacionais. Os bens comuns naturais, dos quais também dependem os Povos Cerradeiros, entram em disputa entre os interesses hegemônicos e os camponeses. Por consequência, o uso e o controle da água, da terra e do subsolo despertam o conflito de classes sobre os territórios do Cerrado em Goiás (GONÇALVES, 2016).

O pesquisador Altair Sales Barbosa, em entrevista realizada em 04/10/2014 para o Jornal Opção, relata a importância do Cerrado no contexto da sociobiodiversidade nacional e internacional. Segundo Barbosa (2014) o bioma está em vias de extinção, ou seja, não é possível recuperá-lo diante do contexto da implementação do agrohidronegócio. O entrevistado explica que no Cerrado há vários elementos interligados, por exemplo, o solo depende de um tipo de clima, o tropical subúmido, algumas sementes dependem de animais específicos do Cerrado, muitos quase extintos, para germinarem. Essas conexões entre vários elementos do bioma fazem com que o Cerrado seja complexo de ser recuperado.

Isso significa que já chegou em seu clímax evolutivo. Ou seja, uma vez degradado não vai mais se recuperar na plenitude de sua biodiversidade. Por isso é que falamos que o Cerrado é uma matriz ambiental que já se encontra em vias de extinção. Onde houve modificação do solo a vegetação do Cerrado não brota mais (BARBOSA, 2014, n.p).

Estudos Geográficos, Rio Claro, 17: 27-42, jan./jun. $2019 \quad$ (ISSN 1678-698X) http://www.periodicos.rc.biblioteca.unesp.br/index.php/estgeo 
Outra complexidade sublinhada por Barbosa (2014) é a questão das águas. Muitas bacias hidrográficas do continente sul-americano dependem do Cerrado para existir. Vários cursos d'água nascem dos aquíferos, onde sua área de recarga esta intrinsecamente ligada ao bioma. A vegetação do Cerrado absorve as águas da chuva. Suas raízes complexas de sistema radicular alimentam o lençol artesiano. Segundo o pesquisador, dez pequenos rios do Cerrado, em média, desaparecem por ano. Ou seja, os principais rios que formam as bacias estão diminuindo a cada ano por ausência da vegetação nativa.

Porto-Gonçalves (2006a) considera que a análise da água necessita da sua geograficidade, ou seja, a inserção concreta na sociedade, considerando as escalas imbuídas no processo de articulação ambiental e político. Além disso, a questão dos conflitos pela água está, segundo Mendonça (2015), no processo de expansão das fronteiras do agrohidronegócio no Cerrado. O sul goiano, por exemplo, se destaca pela territorialização da agricultura capitalista moderna, projetos hidroenergéticos e mineradoras (Mapa 1). Mudanças espaciais ocorrem por conta da implantação do agrohidronegócio originando uma intensa mobilidade geográfica do capital e do trabalho.

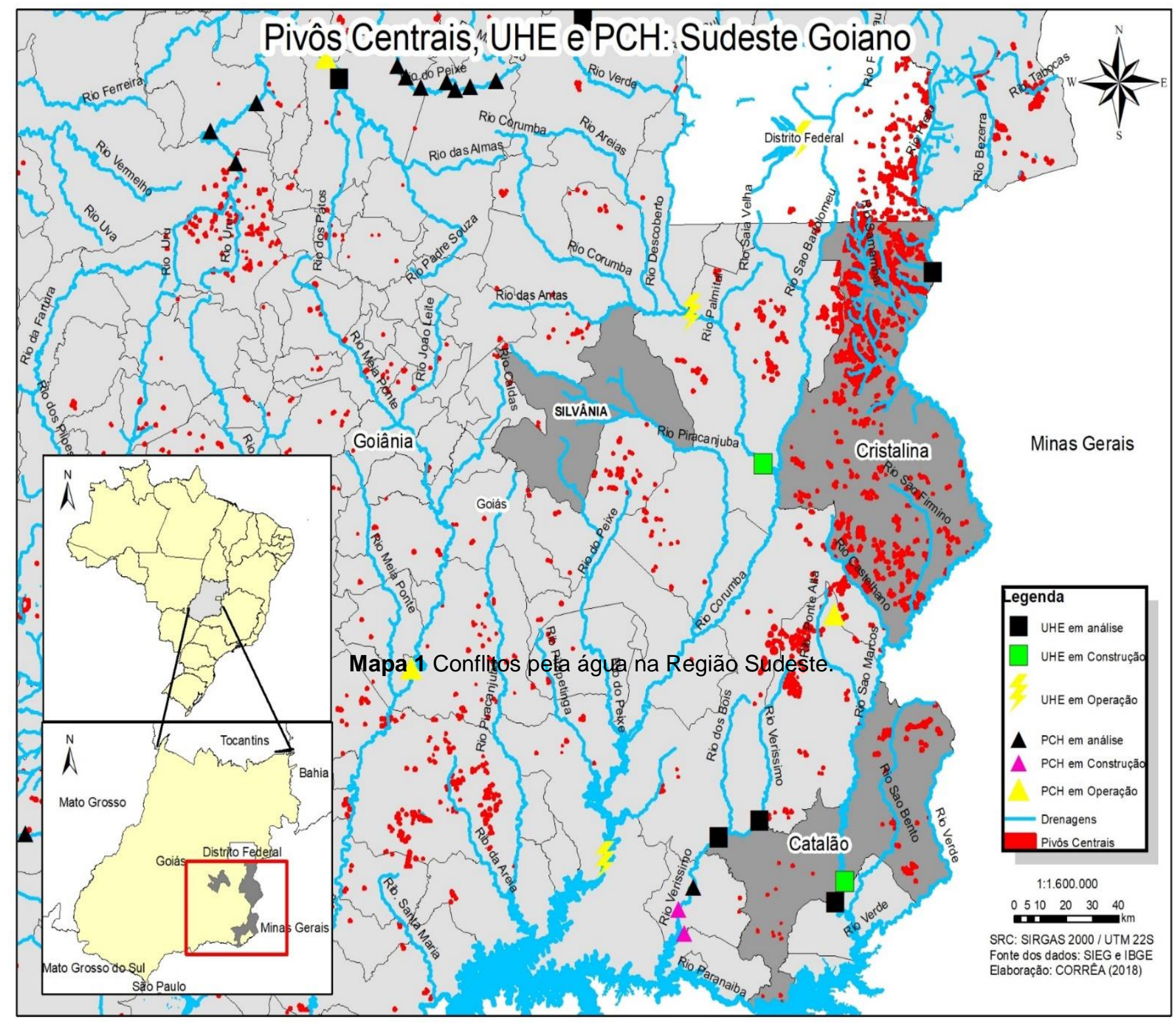

Estudos Geográficos, Rio Claro, 17: 27-42, jan./jun. 2019 (ISSN 1678-698X) http://www.periodicos.rc.biblioteca.unesp.br/index.php/estgeo 
A agricultura de alta escala utiliza a água para produzir commodities e, além disso, para a produção de energia elétrica são necessárias barragens, estas que, também são imprescindíveis para o abastecimento público e para a irrigação. A noção de agrohidronegócio foi elaborado dentro dessa perspectiva, com o controle da terra associado a água e, ambas inseridas nas escalas de produção de mercadorias, deixando de ser um bem público, pois são apropriadas pelos atores hegemônicos. Nos Mapas 1, 2 e 3 estão apontadas as problemáticas acerca do agrohidronegócio que corrobora esse argumento.

Como apontado no Mapa 1, pode-se observar que o ocorrido na região está relacionado à falta de planejamento do Estado e ao uso indiscriminado dos recursos hídricos pelos atores hegemônicos. A quantia de pivôs centrais na região do município de Cristalina (GO) e no Distrito Federal e os projetos hidroenergéticos afogam em problemas a região. Há duas Usinas Hidrolétricas em construção. Uma próxima à Cristalina (UHE Corumbá III) e a outra em Catalão (UHE Serra do Facão), duas usinas em operação entre o DF (UHE Paranoá) e o Munícipio de Luziânia (UHE Corumbá IV) e outra PCH (Lago Azul) no munícipio de Cristalina.

Problemas relacionados aos conflitos hídricos também são recorrentes, segundo Gonçalves (2016) nos municípios de Catalão/Ouvidor (GO) envolvendo grandes projetos de mineração e comunidades camponesas. A mineração, a indústria automobilística, as Pequenas Centrais Hidroelétricas $(\mathrm{PCH})$ e Usina Hidroelétrica (UHE) em operação e os projetos vindouros para manutenção desses negócios podem agudizar os conflitos socioambientais no campo e na cidade.

Com a territorialização da agricultura capitalista e o uso de técnicas de irrigação nos territórios do Cerrado os problemas ambientais envolvendo os usos das águas tendem a se agravar. Barbosa (2014) afirmou que ainda é possível utilizar a irrigação, pois ainda há uma reserva nos aquíferos, porém essa reserva está findando.

Estamos colhendo os frutos da ocupação desenfreada que o agronegócio impôs ao Cerrado a partir dos anos 1970: entraram nas áreas de recarga dos aquíferos e, quando vêm as chuvas, as águas não conseguem infiltrar como antes e, como consequência, o nível desses aquíferos vai caindo a cada ano. Vai chegar um tempo, não muito distante, em que não haverá mais água para alimentar os rios. Então, esses rios vão desaparecer (BARBOSA, 2014, n.p).

Segundo Campos Filho (2010), o método de irrigação com pivôs centrais é altamente dispendioso. A água é jorrada de forma intensiva e acentua o processo de salinização do solo, além de ser desperdiçado $30 \%$ no processo de evaporação. Esse método de irrigação se tornou a principal alternativa para aumentar as produções agrícolas no Bioma-Território Cerrado. Fomentando essa ideia, estudos da Agência Nacional de Águas (ANA) relatam que $72 \%$ da água utilizada no país são do processo de irrigação e, em Goiás, a Secretaria da Fazenda (Sefaz) indicou que em 2016 tinham 3.326 pivôs centrais no estado e apenas 179 licenças emitidas em 10 anos:

A retirada de água passará de $18,3 \%$ de tudo que é utilizado para irrigar lavouras, hoje, para uma representação de $27 \%$ - um aumento absoluto de 177 mil litros por segundo para 361 mil litros por segundo (+104\%). A área irrigada por pivôs aumentará de 19,9\% em relação ao total do que é irrigado hoje, no Brasil, para $28,6 \%$, tornando-se a maior parcela dentre todos os sistemas de irrigação. O Leste goiano,

Estudos Geográficos, Rio Claro, 17: 27-42, jan./jun. 2019 (ISSN 1678-698X) http://www.periodicos.rc.biblioteca.unesp.br/index.php/estgeo 
onde fica Cristalina (GO), aparece entre as regiões de intensificação notável e todo 0 Estado é classificado como polo em desenvolvimento e que tende a apresentar demandas expressivas no futuro (RODRIGUES, 2018, on-line).

A quantidade de pivôs centrais segundo informações oficiais do governo estadual, fornecidas pelo Sistema Estadual de Geoinformações de Goiás (SIEGGO), está longe do contexto real. No Mapa 2 é possível observar que há registrado em Jussara apenas 1 pivô central, sendo que há denúncias de pivôs irregulares.

Como exemplo, Lima (2017) reportou e que foram atuados 70 pivôs ilegais no interior de Goiás. Rodrigues (2018) relatou que, na região do Oeste de Goiás, o município de Jussara possui 114 pivôs, sendo que apenas 1 licença foi emitida entre 2008 e 2017, dado também visível no Mapa 2. Em 2017 um fazendeiro, no mesmo município, foi atuado em $R \$ 4,3$ milhões por captação irregular de um afluente do Rio Araguaia. O sistema captava 11 mil metros cúbicos de água por hora (11 milhões de litros por hora), segundo notícia do Jornal G1 em 06/03/2017, quantia suficiente para abastecer todo o município de Goiânia, por exemplo.

\section{Quadro 1 - Os conflitos pela água em Goiás - 2016}

\begin{tabular}{|c|c|c|c|c|}
\hline Municípios & Nome do Lugar & Famílias & $\begin{array}{l}\text { Tipo do } \\
\text { Conflito }\end{array}$ & Situação do Conflito \\
\hline Caiapônia & Assentamento Cachoeira Bonita & 3 & $\begin{array}{l}\text { Apropriação } \\
\text { Particular }\end{array}$ & $\begin{array}{c}\text { Diminuição do acesso } \\
\text { à Áqua }\end{array}$ \\
\hline Caiapônia & Assentamento Morrinhos & 3 & $\begin{array}{l}\text { Apropriação } \\
\text { Particular }\end{array}$ & $\begin{array}{c}\text { Diminuição do acesso } \\
\text { à Água }\end{array}$ \\
\hline $\begin{array}{l}\text { Flores de } \\
\text { Goiás }\end{array}$ & $\begin{array}{c}\text { Assento Caiçara/Com. } \\
\text { Gameleira }\end{array}$ & 250 & $\begin{array}{l}\text { Apropriação } \\
\text { Particular }\end{array}$ & $\begin{array}{c}\text { Diminuição do acesso } \\
\text { à Água }\end{array}$ \\
\hline laciara & $\begin{array}{c}\text { Com. } \\
\text { Levantado/Salina/Belo/Córrego } \\
\text { Brejo do Fogo }\end{array}$ & 350 & $\begin{array}{l}\text { Apropriação } \\
\text { Particular }\end{array}$ & $\begin{array}{l}\text { Diminuição do acesso } \\
\text { à Água }\end{array}$ \\
\hline laciara & $\begin{array}{c}\text { Com. Quil. Ascorquileia/Rio } \\
\text { Água } \\
\text { Quente }\end{array}$ & $\begin{array}{l}\text { Sem } \\
\text { registro }\end{array}$ & $\begin{array}{c}\text { Uso e } \\
\text { preservação }\end{array}$ & $\begin{array}{c}\text { Diminuição do acesso } \\
\text { à Água }\end{array}$ \\
\hline $\begin{array}{l}\text { Minaçu/ } \\
\text { Niquelândia/ } \\
\text { Uruaçu }\end{array}$ & $\begin{array}{l}\text { Usina Hidrelétrica de Serra da } \\
\text { Mesa }\end{array}$ & 925 & $\begin{array}{l}\text { Barragens e } \\
\text { Açudes }\end{array}$ & $\begin{array}{l}\text { Destruição e ou } \\
\text { poluição }\end{array}$ \\
\hline Piranhas & $\begin{array}{l}\text { P. A. Nascente de São } \\
\text { Domingos }\end{array}$ & 3 & $\begin{array}{c}\text { Uso e } \\
\text { preservação }\end{array}$ & $\begin{array}{l}\text { Destruição e ou } \\
\text { poluição }\end{array}$ \\
\hline \multirow[t]{2}{*}{ Silvânia } & Comunidade João de Deus & 45 & $\begin{array}{c}\text { Uso e } \\
\text { preservação }\end{array}$ & $\begin{array}{c}\text { Diminuição do acesso } \\
\text { à Água }\end{array}$ \\
\hline & TOTAL & 1579 & & \\
\hline
\end{tabular}

Fonte: CPT (2017).

No Quadro 1 pode-se observar que os conflitos do campo em Goiás surgiram na região do Oeste de Goiás nos municípios de Piranhas e Caiapônia totalizando 9 famílias atingidas em assentamentos de reforma agrária.

Por consequência, os conflitos gerados pela apropriação e usos da água também aumentam no campo. Segundo a CPT há uma ampliação de ações de resistência, geralmente coletivas, visando garantir o uso e a preservação das águas contra os interesses privados.

Estudos Geográficos, Rio Claro, 17: 27-42, jan./jun. $2019 \quad$ (ISSN 1678-698X) http://www.periodicos.rc.biblioteca.unesp.br/index.php/estgeo 


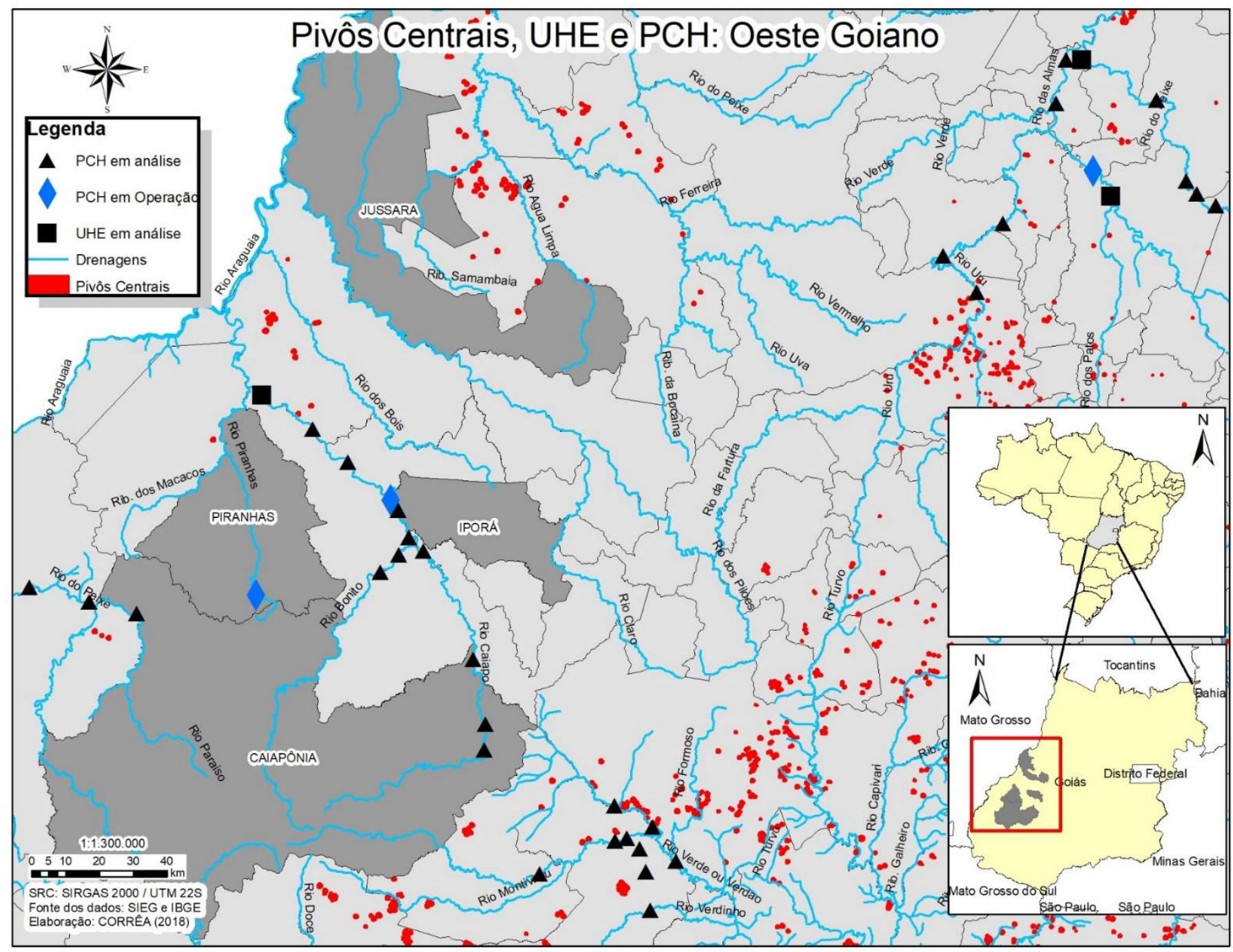

Mapa 2 - Apropriação e controle da água no Oeste goiano

Em Goiás foram 8 conflitos totalizando um número de 1579 famílias atingidas em 2016, no ano anterior não houve registros de conflitos sistematizados pela CPT. No Brasil, a situação dos conflitos por água também foi agravada nos últimos anos.

Apesar de uma incipiente variação de 2014 para 2015, passamos de 28.058 mil famílias envolvidas em 69 conflitos, em 2011, para 44.471 mil famílias em 172 conflitos, em 2016. Disputas territoriais essas, motivadas pelas lógicas antagônicas de gestão, apropriação e uso desse bem natural, ou seja, entre a lógica economicista levada a cabo pela territorialização e/ou monopolização do território pelo capital, materializada, entre outras faces, no uso da água para a morte, e a lógica das diversas e distintas territorialidades dos sujeitos explorados no campo, que travam uma luta incessante pelos seus territórios, pela terra e, por conseguinte, pela água para a vida. Entre 2002 e 2016, chegamos ao absurdo número de 443.043 mil famílias envolvidas em 1.153 conflitos pela água, especializados em praticamente todo o território nacional, dando mostras da dimensão de uma das faces da questão agrária brasileira: 'a apropriação

Estudos Geográficos, Rio Claro, 17: 27-42, jan./jun. $2019 \quad$ (ISSN 1678-698X) http://www.periodicos.rc.biblioteca.unesp.br/index.php/estgeo 
capitalista privada e a devastadora exploração das nossas águas' (CPT, 2017, p.1).

No Quadro 1 observa-se que o maior número de famílias atingidas, 925, pelos conflitos pela água são aquelas relacionadas à Usina Hidrelétrica Serra da Mesa no município de Minaçu, Niquelândia e Uruaçu (Mapa 3). Depois, o número maior de famílias está no município de laciara, 350, e Flores de Goiás, 250, com a situação de conflito de diminuição do acesso à água.

Os projetos do hidronegócio-energético tendem a incrementar os efeitos socioespaciais dos grandes empreendimentos capitalistas nos territórios cerradeiros em Goiás. Portanto, a análise geográfica da territorialização das usinas e da produção de hidroeletricidade em Goiás é apreendida enquanto expressão concreta das ações do capital no interior da "acumulação por espoliação" contemporânea (GONÇALVES, 2016, p. 227).

Em Minaçu, segundo o Movimento dos Atingidos por Barragens (MAB) o conflito ocorrido na UHE Serra da Mesa é antigo. Sua construção ocorreu nos anos 1990 e o início da operação em 1998. Após 21 anos os conflitos pela desocupação ainda persistem. Muitas famílias ainda não receberam indenizações, ribeirinhos mudaram para a cidade e sobrevivem sem sua atividade econômica tradicional. Muitos ainda não resolveram suas vidas em termos socioeconômicos após sua desocupação do lugar de origem.

Os dados da CPT, no Quadro 1, juntamente com os dados dos mapas, apontam que os conflitos no campo poderão aumentar. O Cerrado, dessa forma, está cada vez mais se afirmando como território em disputa, com o agrohidronegócio, as mineradoras e os projetos hidroenergéticos no processo de espoliação do território cerradeiro. Diante desse cenário, quem usufrui dessas infraestruturas e porque os conflitos pela água no campo estão aumentando?

Os problemas relacionados à territorialização do agrohidronegócio causam efeitos socioambientais irreversíveis no território do Cerrado goiano. Os conflitos gerados pelas divergências de classes são consequências desse processo que conta com as práticas e estratégias da acumulação primitiva do capital. "[...] a crescente denúncia de disputas em torno do acesso a água, da diminuição da vazão dos cursos d'água e da qualidade da mesma, pois a cada dia, a contaminação por agrotóxicos e a poluição por outras fontes preocupa os pequenos e médios proprietários" (MENDONÇA, 2015, p. 13). A água está apropriada pelos agentes hegemônicos através das PCHs, UHEs e Pivôs centrais no território de Goiás. Em suma, constata-se que para acumular capital, o controle territorial da água, além da terra e do subsolo, é imprescindível, transformando o Cerrado em um território em disputa.

Estudos Geográficos, Rio Claro, 17: 27-42, jan./jun. $2019 \quad$ (ISSN 1678-698X) http://www.periodicos.rc.biblioteca.unesp.br/index.php/estgeo 


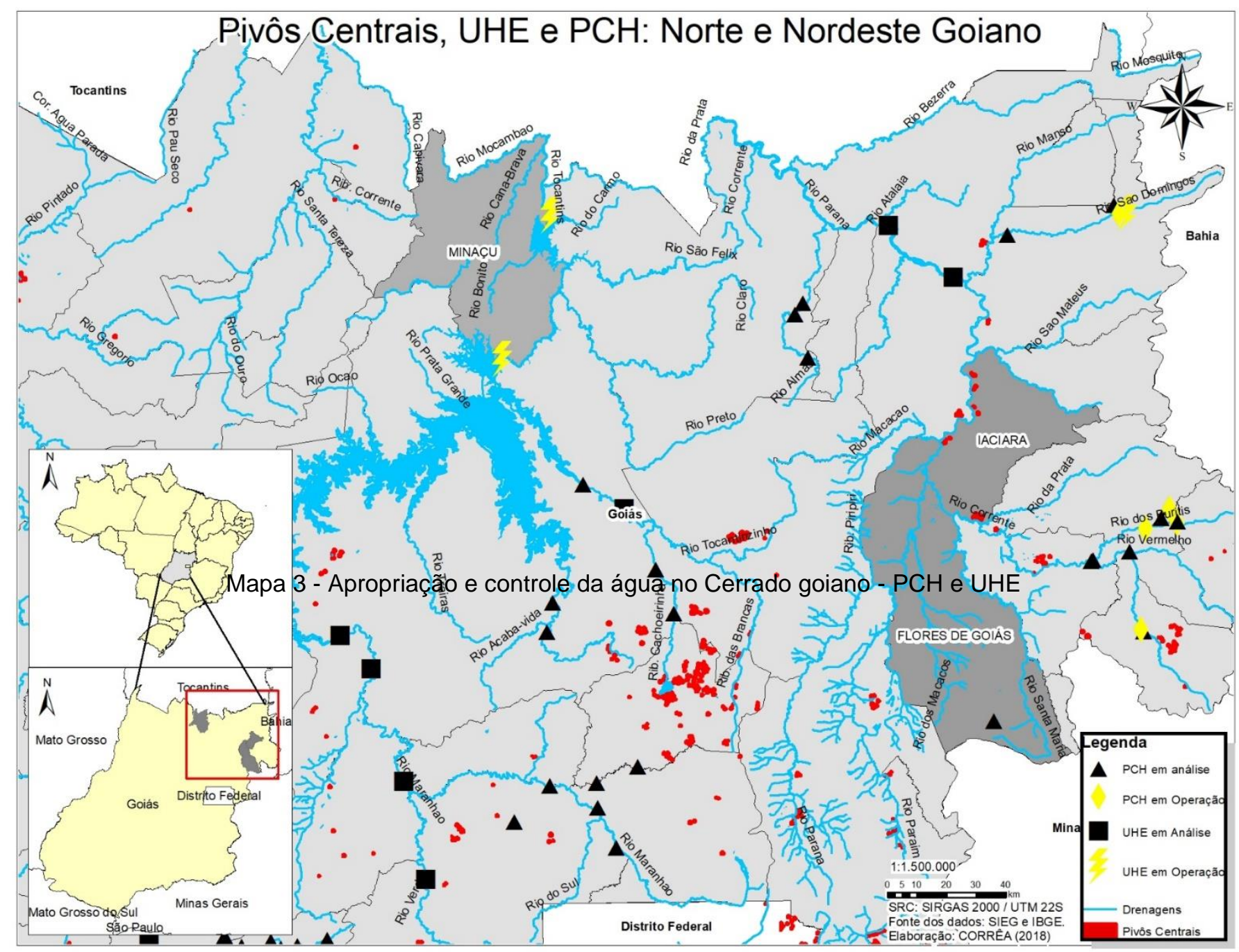

\section{PARA NÃO CONCLUIR}

Partindo das informações oferecidas pela Comissão Pastoral da Terra sobre os conflitos pela água, essa pesquisa analisou os aspectos territoriais e socioambientais para entender a ascensão dos embates ocorridos no campo. Nas análises espaciais dos três mapas elaborados foi possível identificar a falta de planejamento e gestão do estado aos arredores do Distrito Federal e o município de Catalão, sobrecarregando as Bacias Hidrográficas da região, ao contento das transnacionais da mineração, agronegócios e também automobilístico. A segunda análise, observada no Oeste de Goiás é a ausência de fiscalização sobre os municípios, exemplificando o caso de Jussara. E a terceira análise os grandes impactos que as UHE causam nos Povos Cerradeiros.

No processo de acumulação por espoliação, o capital enxerga a natureza como uma grande reserva de valores de usos potencias, usados de forma direta ou indireta, na geração de mercadorias. Dentro do contexto do território cerradeiro, os recursos territoriais e os insumos de tecnologia e ciência contribuem para que esse processo possa ser perpetuado.

A pesquisa problematizadora desta questão é necessária e crítica ao modelo de apropriação privada do território cerradeiro, posta ao lado dos diferentes sujeitos

$$
\text { Estudos Geográficos, Rio Claro, 17: 27-42, jan./jun. } 2019 \text { (ISSN 1678-698X) }
$$


(camponês, indígena, quilombola, ribeirinho etc.), com a intuição de que em seus espaços de existência coletiva possam utilizar a terra e a água conforme a lógica cotidiana da vida em comunidade.

A permanência e a 0 acesso aos bens comuns naturais precisam ser defendidas e assegurados os direitos de existência e dignidade dos trabalhadores.

A intensa produtividade de commodities agrominerais no território do Cerrado goiano obriga o capital a exercer o controle da água, da terra e do subsolo. Para o sucesso dos empreendimentos do agrohidronegócio e da mineração, a intervenção dos recursos hídricos se fez necessária para a acumulação do capital.

A interação entre a terra e a água também é necessária para a expansão das atividades dos trabalhadores camponeses, no entanto as dificuldades para esses sujeitos são maiores, pois enfrentam os conflitos e os interesses hegemônicos territorializados nos seus lugares de existência coletiva.

Nesse contexto, os sujeitos que habitam os território cerradeiro perdem seu espaço para os grandes projetos econômicos, fazendo com que em seu processo de existência e permanência seja pilhado e erodido pela acumulação por espoliação.

Os conflitos pela água, segundo os dados analisados ao longo da pesquisa, são crescentes ao longo dos últimos anos no Brasil e particularmente no território cerradeiro. No Estado de Goiás, os maiores atingidos envolvem a territorialização de usinas hidroelétricas. Logo, o uso intensivo da água através da acumulação por espoliação ameaça, cada vez mais, tirar a autonomia da população camponesa e dos povos tradicionais, agudizando os conflitos pelos recursos hídricos em Goiás.

\section{REFERÊNCIAS}

ÁGUAS DO BRASIL. Os recursos hídricos do Estado de Goiás. Disponível em: http://aguasdobrasil.org/edicao-08/os-recursos-hidricos-do-estado-de-goias.html Acesso em: 13 ago. 2017.

AGENCIA NACIONAL DE ÁGUAS. Atlas de irrigação. Disponível em: http://atlasirrigacao.ana.gov.br/. Acesso em: 14 mar. 2018.

BARBOSA, Altair Sales. O Cerrado está extinto e isso leva ao fim dos rios e dos reservatórios de água. Jornal Opção, Goiânia, 04 de outubro de 2014. Disponível em: https://www.jornalopcao.com.br/entrevistas/o-cerrado-esta-extinto-e-isso-levaao-fim-dos-rios-e-dos-reservatorios-de-agua-16970. Acesso em: 06 de ago. 2017.

BORGES, F. Fazendeiro é indiciado por retirar água de forma irregular do Rio Araguaia, G1, Goiânia, 06 mar. 2017. Disponível em: http://g1.globo.com/goias/noticia/2017/03/fazendeiro-e-indiciado-e-multado-em-r-43mi-por-retirar-agua-do-araguaia.html. Acesso em: 05 nov. 2017.

BRANDÃO, C. Acumulação primitiva permanente e desenvolvimento capitalista no Brasil contemporâneo. In: ALMEIDA, A. W. B. de. et. al. Capitalismo globalizado e recursos territoriais. Rio de Janeiro: Lamparina, 2010. p. 39-100.

CAESB. 550 informações referentes a crise hídrica no Distrito Federal. 2018. Disponível em: https://www.caesb.df.gov.br/8-portal/noticias/550-informacoesreferentes-a-crise-hidrica-no-distrito-federal.html. Acesso em: 13 abr. 2017

Estudos Geográficos, Rio Claro, 17: 27-42, jan./jun. 2019 (ISSN 1678-698X) http://www.periodicos.rc.biblioteca.unesp.br/index.php/estgeo 
CAMPOS FILHO, R.P. Um olhar geopolítico sobre a água no Cerrado: apontamentos para uma preocupação estratégica. In: CASTILHO, D.; PELA, M. Cerrados: perspectivas e olhares. Goiânia: Editora Vieira, 2010. p. 93-112.

CASTILHO, D.; CHAVEIRO, E.F. Por uma análise territorial do Cerrado. In: CASTILHO, D.; PELA, M. Cerrados: perspectivas e olhares. Goiânia: Editora Vieira, 2010. p. 35-50.

CHAVEIRO, E.F. A URBANIZAÇÃO DO CERRADO: ESPAÇOS INDOMÁVEIS, ESPAÇOS DEPRIMIDOS. Revista UFG / Dezembro 2010 / Ano XII no 9

COMISSÃO PASTORAL DA TERRA. Conflitos pela água 2016-2015. Disponível em: $\quad$ https://www.cptnacional.org.br/component/jdownloads/send/58-dados2016/14051-imprensa-conflitos-pela-agua-2016-2015. Acesso em: 13 ago. 2017.

COMISSÃO PASTORAL DA TERRA. Conflitos pela água quase triplicam em seis anos.

Disponível em:

https://www.cptnacional.org.br/component/jdownloads/send/58-dados-2016/14056conflitos-pela-agua-quase-triplicam-em-seis-anos-cpt-assessoria-de-comunicacao. Acesso em: 13 ago. 2017.

GONÇALVES, R.J.A.F. No horizonte, a exaustão: disputas pelo subsolo e efeitos socioespaciais dos grandes projetos de extrativismo mineral em Goiás. 2016. 515 f. Tese (Doutorado em Geografia), Programa de Pós-Graduação em Geografia, Instituto de Estudos Socioambientais, Universidade Federal de Goiás, Goiânia, 2016.

HARVEY, D. O enigma do capital: e as crises do capitalismo. Trad. João Alexandre Peschanski. São Paulo: Boitempo, 2011.

HARVEY, D. O novo imperialismo. Tradução de Adail Sobral e Maria Stela Gonçalves. 7.ed. São Paulo: Edições Loyola, 2013.

HARVEY, D. 17 Contradições e o fim do capitalismo. Tradução de Rogério Bettoni. São Paulo, SP: Boitempo, 2016.

JORNAL OPÇÃO. O Cerrado está extinto e isso leva ao fim dos rios e dos reservatórios de água. $2014 . \quad$ Disponível em: https://www.jornalopcao.com.br/entrevistas/o-cerrado-esta-extinto-e-isso-leva-ao-fimdos-rios-e-dos-reservatorios-de-agua-16970/. Acesso em: 09 mai. 2018.

LENCIONI, S. Acumulação primitiva: um processo atuante na sociedade contemporânea. 2012. Disponível em: http://confins.revues.org/7424. Acesso em 07, jul. de 2017.

LUXEMBURGO, R. A acumulação do capital: contribuições ao estudo econômico do imperialismo. Tradução de Marijane Vieira Lisboa e Otto Erich Walter Maas. 2.ed. São Paulo: Nova Cultural, 1985.

Estudos Geográficos, Rio Claro, 17: 27-42, jan./jun. $2019 \quad$ (ISSN 1678-698X) http://www.periodicos.rc.biblioteca.unesp.br/index.php/estgeo 
MARX, K. O Capital: Crítica da economia política. Livro I: o processo de produção de capital. Tradução Rubens Enderle. 1aㅡ ed. São Paulo: Boitempo, 2013.

MENDONÇA, M. R. A urdidura espacial do capital e do trabalho no Cerrado do Sudeste Goiano. 459p. [Tese de Doutorado]. Faculdade de Ciência e Tecnologia, Universidade Estadual Paulista, 2004.

MENDONÇA, M. R. Complexidade do espaço agrário brasileiro: o agrohidronegócio e as (re)existências dos Povos Cerradeiros. Terra Livre, São Paulo/SP Ano 26, V.1, n. 34 p. 189-202 Jan-Jun/2010.

MENDONÇA, M. R. As transformações espaciais no campo e os conflitos pelo acesso a terra e a água: as novas territorialidades do agrohidronegócio em Goiás. Revista Pegada, v. 16, número especial, p. 3-15, mai.2015.

MOREIRA, R. O capítulo 24 e o segredo da atualidade analítico-estrutural do capital de Marx. Revista da Associação Nacional de Pós-graduação e Pesquisa em Geografa (Anpege), p. 9-19, V.11, n.16, jul-dez. 2015.

LIMA, C. Setenta autuações por uso irregular da água. O Popular, Goiânia, 14 set. 2017. Disponível em: https://www.opopular.com.br/editorias/cidades/setentaautua\%C3\%A7\%C3\%B5es-por-uso-irregular-da-\%C3\%A1gua-1.1348129. Acesso em: 15 abr. 2018.

PORTO-GONÇALVES, C. W. Água não se Nega a Ninguém (A necessidade de ouvir vozes). In: PARREIRA C.; ALIMONDA H. Políticas Públicas Ambientais Latino-Americanas. Brasília: FLACSO, 2006a. p. 115-144.

PORTO-GONÇALVES, C. W. A globalização da natureza e a natureza da globalização. Rio de Janeiro: Civilização Brasileira, 2006b.

PORTO-GONÇALVES, C.W. O desafio ambiental. 3. ed. Rio de Janeiro, Record. 2013.

PINTO, M. P.; DINIZ-FILHO, J. A. F. Biodiversidade no Cerrado. In: ALMEIDA, Maria Geralda de. Tantos Cerrados. Goiânia: Vieira, 2005. p. 115-128.

RAFFESTIN, C. Por uma geografia do poder. São Paulo: Editora Ática, 1993.

RODRIGUES, G. Pivôs Centrais longe da legalidade, O Popular, Goiânia, 13 jan. 2018. Disponível em: https://www.opopular.com.br/editorias/cidades/piv\%C3\%B4scentrais-longe-da-legalidade-1.1438302\# = Acesso em: 04 abr. 2018.

SANTOS, M. A natureza do espaço. São Paulo: Editora da Universidade de São Paulo, 2004.

SOUZA, J. G. Local-Global: Território, finanças e acumulação na agricultura. In: LAMOSO, L.P. Temas de desenvolvimento econômico brasileiro e suas articulações com o Mato Grosso do Sul. Curitiba: Ithala, 2016. p. 55-95.

Estudos Geográficos, Rio Claro, 17: 27-42, jan./jun. $2019 \quad$ (ISSN 1678-698X) http://www.periodicos.rc.biblioteca.unesp.br/index.php/estgeo 
O território do cerrado em disputa...

THOMAZ JUNIOR, A. O agrohidronegócio no centro das disputas territoriais e de classe no Brasil do século XXI. Campo território: revista de geografia agrária, v. 5, n. 10, p. 92-122, ago. 2010.

Estudos Geográficos, Rio Claro, 17: 27-42, jan./jun. $2019 \quad$ (ISSN 1678-698X) 